Células-tronco mesenquimais: características, cultivo e uso na Medicina Veterinária

Gabrielle Rosemblit Martins ${ }^{1 *}$, Maria Fátima da Silva Teixeira ${ }^{1}$, Rosivaldo Quirino Beserra Junior', Ronaldo Pereira Dias ${ }^{1}$, Tereza D’ávila de Freitas Aguiar ${ }^{1}$, Rebeca Cavalcante Marinho ${ }^{1}$, Ana Raquel Almeida Pinheiro'.

Resumo: As células-tronco mesenquimais são células adultas indiferenciadas com grande plasticidade, capazes de originar tecidos mesodermais e não mesodermais, produzindo qualquer tipo celular necessário num processo de reparação. Devido a essas características essas células vêm ganhando muito atenção das pesquisas voltadas tanto para humanos como para animais, buscando-se protocolos padrões de separação, cultivo e diferenciação das mesmas para que possam ser utilizadas em diversas terapias celulares. O principal foco atual de interesse da terapia celular é a medicina regenerativa, em que se busca a substituição de células ou tecido lesado, senescentes ou perdidos para restaurar sua função, sendo as terapias com células-tronco, as que despertam mais interesse na sociedade. Atualmente, as pesquisas em Medicina Veterinária têm utilizados camundongos, ratos, gatos, cães, cavalos, ovelhas e cabras, isolando esse tipo celular, principalmente, da medula óssea, tecido adiposo, cordão umbilical e fluido amniótico.

Palavras-chave: Medula óssea, animais, terapias, multipotentes.

\title{
Mesenchymal stem cells: characteristics, cultivation and use in Veterinary Medicine
}

Abstract: The mesenchymal stem cells are undifferentiated adult cells with high plasticity, capable of causing tissue mesodermais and not mesodermais, producing any cell type needed in the repair process. Due to such characteristics these cells have been gaining much attention from research directed both to humans and to animals, seeking standards protocols to separation, cultivation and differentiation of the same so that they can be used in various cell therapies. The main current focus of interest in the cell therapy is regenerative medicine, which seeks to replace damaged cells or tissue, senescent or lost to restore their function, and therapies with stem cells, those that arouse more interest in society. Currently, research in veterinary medicine have used mice, rats, cats, dogs, horses, sheep and goats, 
isolating this cell type, mainly bone marrow, adipose tissue, umbilical cord and amniotic fluid.

Keywords: Bone marrow, animals, therapies, multipotent

1345 Programa de Pós-graduação em Ciências Veterinárias da Faculdade de Veterinária da Universidade Estadual do Ceará (UECE), email: rmgabrielle@ hotmail.com, junior_medvet2009@hotmail.com, ronaldodias01@yahoo.com.br, davilavet@gmail.com

${ }^{2}$ Doutora responsável pelo Laboratório de Virologia do Programa de Pós-graduação em Ciências Veterinárias da Faculdade de Veterinária da Universidade Estadual do Ceará (UECE), orientadora, email: mfteixeira@ hotmail.com, Médica Veterinária

${ }^{6}$ Mestre pelo Programa de Pós-graduação em Ciências Veterinárias da Faculdade de Veterinária da Universidade Estadual do Ceará (UECE), email:, email: beca.marinho@hotmail.com, Médica Veterinária

${ }^{7}$ Aluna de iniciação cientifica do Programa de Pós-graduação em Ciências Veterinárias da Faculdade de Veterinária da Universidade Estadual do Ceará (UECE), email: kel almeida92@ hotmail.com, curso: Medicina Veterinária.

Autor para correspondência. E. Mail: *mfteixeira@ hotmail.com

Recebido em 10/03/2014. Aceito em 14/05/2014

\section{Introdução}

Células-tronco são células

indiferenciadas que possuem capacidade de autorrenovação, sendo capazes de se multiplicar mantendo o seu estado indiferenciado, proporcionando uma reposição ativa de sua população nos tecidos; além de ter capacidade de se diferenciar em diversos tipos celulares, possuindo, desta forma, um papel regenerativo quando estes sofrem uma lesão ou injúria (BLAU et al., 2001; FODOR, 2003).
A proliferação das células-tronco (autorrenovação) ocorre por meio de mitoses sendo responsável por garantir um número adequado de células-tronco em determinado local do organismo. Com relação à regeneração de tecidos esta ocorre quando as células-tronco presentes em diversos locais do organismo recebem sinais específicos para que ocorram divisão e reposição de células perdidas, como no caso de uma lesão tecidual. A diferenciação é a capacidade particular que estas células apresentam de gerar tipos 
Martins et al., Revista Brasileira de Higiene e Sanidade Animal (v.8, n.2) p. 181 - 202, abr - jun (2014

celulares distintos, sob o estimulo bioquímico, hormonal e mecânico adequado, in vitro ou in vivo (CSAKI et al., 2007).

Tomando-se como referencial os aspectos relativos ao potencial de diferenciação das células-tronco estas podem ser classificadas em: pluripotentes - podem gerar todos os diferentes tipos celulares, como as células da massa celular interna do blastocisto, e multipotentes precursoras de diferentes tipos celulares de uma mesma linhagem do tecido onde se insere, como por exemplo, as célulastronco hematopoiéticas. As células-tronco ainda podem ser classificadas como oligopotentes, que podem originar células de diferentes linhagens celulares de um mesmo tecido, como as células-tronco neurais. Existem também aquelas que originam apenas um tipo celular, com função repositora, como as células-tronco da epiderme, chamadas unipotentes (FRIEL et al., 2005).
Essa série de características particulares das células-tronco determina o seu importante papel na terapia de diversas doenças, sendo utilizadas tanto na medicina humana, como na medicina veterinária, e em sua maioria obtidas, pósnatal, de amostras da medula óssea (BYDLOWSKI et al., 2009).

Existem dois tipos de célulastronco potencialmente úteis para medicina: células-tronco embrionárias e célulastronco adultas. $\mathrm{O}$ potencial de diferenciação das primeiras está bem caracterizado em camundongos e em humanos, no entanto seu uso em terapia celular e em pesquisa tem sido dificultado por questões de histocompatibilidade, segurança e ética. Em contraste, as célulastronco adultas não apresentam estes empecilhos, apesar da extensão de sua plasticidade ainda estar sob investigação (PEREIRA, 2008).

As células-tronco embrionárias são classificadas como totipotentes ou 
Martins et al., Revista Brasileira de Higiene e Sanidade Animal (v.8, n.2) p. 181 - 202, abr - jun (2014

pluripotentes, sendo encontradas durante o desenvolvimento do pré-embrião. Já as células-tronco adultas ou células-tronco somáticas, são multipotentes, não especializadas e já foram identificadas em diferentes órgãos e tecidos, como sangue periférico, tecido adiposo, sistema nervoso central, músculo, epitélio intestinal, pele, dente e medula óssea, onde participam da homeostase tecidual, gerando novas células devido à renovação fisiológica ou injúria sofrida (BJORNSON et al., 1999; CLARKE et al, 2000; CSAKI et al., 2007). As primeiras células-tronco adultas identificadas foram às precursoras hematopoéticas, responsáveis pela produção das células sanguíneas na medula óssea (ZAGO, 2005).

Atualmente, dentre as célulastronco adultas estudadas, as células-tronco mesenquimais (CTMs) apresentam maior plasticidade, originando tecidos mesodermais e não mesodermais (ZAGO \& COVAS, 2004; MEIRELLES et al.,
2006). São células multipotentes, com alta capacidade de se renovar e diferenciar em células de diversas linhagens de tecido conjuntivo (BITTENCOURT et al., 2006) como osteoblastos, condrócitos e adipócitos (KADIYALA et al., 1997a), além de poderem ser obtidas de diferentes tecidos como medula óssea e tecido adiposo (REBELATTO et al., 2008).

\section{Células-tronco mesenquimais (CMT)}

As CMTs tem particular importância na medula óssea, sendo responsável pela manutenção do "nicho da célula-tronco hematopoética", regulando sua autorrenovação e diferenciação in vivo (WILSON \& TRUMPP, 2006), estas CMT são formadas por um grupo heterogêneo de células não hematopoéticas, que inclui fibroblastos, adipócitos, precursores osteogênicos e células reticulares (LAZZAROTTO-SILVA, 2009).

A presença de células-tronco não hematopoéticas na medula óssea foi primeiramente sugerida pelo patologista 
alemão Julius Clonheim, em 1867, quando sugeriu que a medula óssea pudesse ser a fonte de fibroblastos que depositam fibras colágenas como parte do processo normal de reparo (BYDLOWSKI et al., 2009).

Porém, a comprovação da existência desse tipo de célula na medula óssea só ocorreu após os estudos de (FRIEDENSTEIN et al., 1966), através da demonstração de uma cultura de células da medula óssea que tinha capacidade de aderir ao plástico, formar colônias em formato de fuso e semelhante a fibroblastos, sendo estas colônias derivadas de uma única célula precursora, designada Unidade Formadora de Colônia Fibroblásticas (UFC-F) (PROCKOP, 1997).

As CTMs são consideradas uma linhagem de células-tronco somáticas e estão presentes em pequenas quantidades em regiões perivasculares de todos os tecidos adultos, incluindo a medula óssea, o tecido adiposo, o periósteo, o tecido muscular e os órgãos parenquimatosos (MAMBELLI et al., 1999; MEIRELLES et al., 2008; ZUCCONI et al., 2009). A medula óssea constitui um dos principais sítios doadores dessas células, assim como de células-tronco hematopoéticas e endoteliais (PITTENGER et al., 1999; MINGUELL et al., 2000).

Inicialmente as CTMs foram isoladas do baço e timo. Subsequentemente, aspirados da medula óssea foram considerados amostras de eleição, por serem mais acessíveis e apresentarem fontes ricas em CTMs. Atualmente, essas vêm sendo isoladas de vários locais do organismo humano e animal, incluindo cartilagem, periósteo, sinóvia, líquido sinovial, músculos e tendões (FRIEDENSTEIN et. al., 1966), cérebro (UCHIDA et al., 2000), tecido adiposo (ZUK et al., 2001), sangue do cordão umbilical (LEE et al., 2004), e em tecidos fetais como sangue, fígado, medula óssea e do rim (MIAO et al., 2006). 
Todavia, apresentam pouca quantidade desse tipo celular comparado com a medula óssea, além de ainda não estarem bem estabelecidas às condições ideais de cultivo (WEXLER et. al., 2003).

As CTMs caracterizam-se por ser uma população de células multipotentes capazes de se diferenciar e produzir qualquer tipo celular necessário num processo de reparação, como osteoblastos, condroblastos, hepatócitos, neurônios, células epiteliais, renais, cardíacas, dentre outras (PITTENGER et al., 1999). Tais características de plasticidade sugerem que esse tipo celular é o responsável pela manutenção de todos os tecidos do organismo (CAPLAN, 2009).

As CTMs expressam um grande número de moléculas bioativas como as moléculas de adesão, as proteínas de matriz extracelular, as citocinas e os receptores para fatores de crescimento, permitindo interações com demais células (HUSS, 2000; BOBIS et al., 2006). Essas moléculas atuam modulando a resposta inflamatória, angiogênese e mitose das células envolvidas no processo de reparação tecidual (WAN et al., 2008; CAPLAN, 2009).

As CTMs, uma vez isoladas, independente do tecido de origem, podem ser utilizadas principalmente em terapias celulares. A forma mais antiga de terapia celular é a transfusão de componentes sanguíneos, um dos procedimentos terapêuticos mais amplamente utilizados no mundo todo. Porém, o principal foco atual de interesse da terapia celular é a medicina regenerativa, em que se busca a substituição de células ou tecidos lesado, senescentes ou perdidos para restaurar sua função. As formas de terapia celular que despertam as maiores esperanças da comunidade científica e da sociedade em geral são as terapias com células-tronco (ZAGO, 2005).

\section{Cultivo de células-tronco}


O cultivo celular é um conjunto de técnicas que permitem cultivar ou manter células isoladas fora do organismo, e tem como objetivo a expansão do número dessas células. Essa expansão é realizada pela manutenção das células em frascos ou placas de cultivo, em meio apropriado, suplementado com diversos fatores, até que estas atinjam 80-85\% de confluência, quando são submetidas à tripsinização, processo no qual são transferidas e expandidas para mais frascos ou frascos maiores, técnica denominada de passagem celular, que permite a ampliação do estoque celular e sua utilização em pesquisas cientificas (FRESHNEY, 2005).

As células isoladas e destinadas ao cultivo celular são mantidas em incubadora a $37^{\circ} \mathrm{C}$ com $5 \% \quad \mathrm{CO}_{2}$, o que facilita a manutenção do $\mathrm{pH}$ do meio, permitindo que as trocas das células com o meio sejam mais eficientes (FRESHNEY, 2005). Diversos meios de cultivo já foram testados para manutenção das CTMs, dentre eles MEM, Meio Essencial Mínimo modificado por Dulbeco (DMEM), RPMI1640, Meio Basal de Eagle (BME), dentre outros, acrescidos de Soro Fetal Bovino (SFB), normalmente na concentração de 10- $20 \%$, sendo a escolha do meio uma variável importante para o sucesso do crescimento e diferenciação das CTMs em cultivos celulares in vitro (TAPP et al., 2009).

As CTMs podem ser cultivadas em meio de cultivo completo, em frascos ou placas de cultura, nos quais elas se aderem, começam a se proliferar e formam as UFCF (KRAMPERA et al., 2006). Essas células se tornam uma população aderente cada vez mais homogênea e de acordo com estudos de caracterização com CTMs humanas, tem potencial para se proliferarem sem se diferenciarem por até 40 passagens (HORWITZ et al., 1999; PITTENGER et al., 1999).

A separação de células para o cultivo pode ser efetuada através de 
Martins et al., Revista Brasileira de Higiene e Sanidade Animal (v.8, n.2) p. 181 - 202, abr - jun (2014

diversos gradientes de densidade de alto peso molecular. Dentre eles estão o Ficoll-

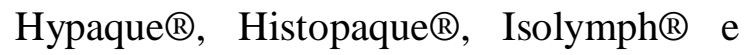
Nycomed®, os quais apresentam a função de isolar linfócitos e células mononucleares do sangue periférico e da medula óssea (ISLAM, 1995). O gradiente de densidade Ficoll tem merecido destaque, por ser de fácil aplicabilidade, rápido e favorecer a concentração de células mononucleares, atingindo altos níveis de rendimento celular (OLIVEIRA, 2009). O princípio da técnica de separação baseia-se na densidade do gradiente em relação aos linfócitos, monócitos e plaquetas, os quais não conseguem penetrar pelo gradiente. Esses se depositam na interface entre o Ficoll e o plasma, formando o chamado "anel celular". A migração celular durante o processo de centrifugação com o Ficoll resulta na formação de camadas contendo diferentes tipos celulares (Amersham BIOSCIENCES, 2002).
Nos primeiros estudos para separação de células-tronco foi utilizado Percoll®, que apresenta o mesmo funcionamento dos outros gradientes de densidade apresentados. Com o mesmo propósito, WAGNER et al. (2005) utilizaram Biocoll@, com sucesso, para isolamento da medula óssea de humanos e DVORAKOVA et al. (2008) utilizaram Ficoll-paque ${ }^{\circledR}$. Sung et al. (2008) realizaram isolamento das CTMs da medula óssea de camundongos com Histopaque ${ }^{\circledR}$.

Em uma variação do protocolo original de separação e isolamento de células-tronco, a medula óssea coletada de camundongo é centrifugada e as células resultantes são lavadas com meio de cultivo e então semeadas em frasco de cultivo (TROPEL et al., 2004; Lennon \& Caplan, 2006). Nesse caso, as células não aderentes são removidas após três dias, removendo-se dessa forma as células 
sanguíneas e excluindo-se o uso de um separador por gradiente de densidade.

O cultivo de CTMs é feito selecionando-se as células com propriedade de adesão ao plástico, sendo que as células que permanecem em suspensão são facilmente removidas. Os outros tipos celulares "contaminantes" como os macrófagos, são eliminados após um determinado número de passagens em cultura (JAVAZON et. al., 2004). Estas células aderentes são heterogêneas e ficam inativas por dois a quatro dias, quando começam a proliferar rapidamente. Após várias passagens em cultura, as células aderentes se tornam fibroblastoides (BYDLOWSKI et al., 2009).

Toda CTM não diferenciada exibe morfologia fibroblástica e padrão característico de marcadores de superfície (MARTIN et al., 2002). Esses critérios, juntamente com a habilidade de se diferenciar em diversos tipos celulares, têm sido usados para definição de um protótipo de fenótipo para CTMs que seja consistente entre as diferentes espécies (MARTIN et al., 2002), incluindo rato (WOODBURY et al., 2000), camundongo (PHINNEY et al., 1999), cão (KADIYALA et al., 1997b) e humano (PITTENGER et al., 1999).

O padrão ouro para a identificação das CTMs foi estabelecido por PITTENGER et al. (1999) como “fibroblastos capazes de se diferenciarem em três linhagens principais: osteoblástica, adipocítica e condrocítica". Essa definição funcional permite a afirmação da natureza de uma população das CTMs na ausência de marcadores específicos. Além desses tipos, as CTMs podem ser expandidas $e x$ vivo e induzidas in vitro a se diferenciar em diferentes tipos celulares esqueléticos encontrados em vários estágios do desenvolvimento, assim como em sítios anatômicos específicos. Tais tipos celulares incluem osteoblastos (osso), condrócitos (cartilagem), adipócitos 
Martins et al., Revista Brasileira de Higiene e Sanidade Animal (v.8, n.2) p. 181 - 202, abr - jun (2014

(estroma medular), fibroblastos (periósteo), e células reticulares (estroma medular) (BIANCO et al. 2008). Além de sofrer diferenciação não convencional tanto in vitro como in vivo, formando células do tipo neural, endodermal, e cardiomiócitos, derivadas, portanto, de folhetos embrionários diferentes do mesenquimal.

Laboratorialmente, as células mesenquimais isoladas e posteriormente expandidas podem ser conduzidas a diferenciação em múltiplas linhagens fenotípicas, quando cultivadas em meios específicos contendo fatores de crescimento ou outras substâncias como dexametasona, indometacina, hidrocortisona e fatores de crescimento de transformação (TGF- $\beta$ ) (JONES et. al., 2002).

Apesar dos avanços obtidos no emprego de células-tronco como auxiliares no tratamento de inúmeras enfermidades, muitos questionamentos ainda não foram esclarecidos. Assim, é possível argumentar que a grande preocupação acerca dos fatores de sucesso e insucesso dos procedimentos de cultura celular tem relação com o número de células obtidas nas colheitas, sua diferenciação e viabilidade nos meios utilizados (PEREIRA et al., 2008), principalmente, quando se trata das células com potencial reparador, as chamadas células-tronco mesenquimais (PROCKOP et al., 2003).

\section{Uso das CTMs na Medicina Veterinária}

Diversos estudos vêm sendo realizados na Medicina Veterinária com o intuito de isolar e caracterizar as CTMs a partir de amostras de vários tecidos celulares, e de diferentes animais. Essas pesquisas têm como objetivos elaborar protocolos padrões para separação, isolamento, cultivo e caracterização destas células, de forma a contribuir para o seu uso em terapias humanas e animais, principalmente no tocante a tratamentos visando à recuperação de lesões, sejam elas ósseas, epiteliais, dentre outras. 
Martins et al., Revista Brasileira de Higiene e Sanidade Animal (v.8, n.2) p. 181 - 202, abr - jun (2014

Inicialmente, os trabalhos provenientes de amostras da medula óssea. envolvendo animais como ratos e Estudos realizados com cães isolaram estas camundongos foram realizados, células da medula óssea (CSAKI et al., principalmente, com objetivo de utilizar um modelo animal para pesquisas com humanos, como os trabalhos de BARROS et al. (2001) que utilizaram células-tronco na reparação de falhas experimentais em rádio de coelhos, e de ARGÔLO NETO (2009) e MONTEIRO (2009) que utilizaram culturas de CTMs marcadas pela proteína fluorescente verde (GFP) em aplicações autógenas in situ, no tratamento de lesões epiteliais de pacientes diabéticos e de lesões ósseas na calota craniana, demonstrando cicatrização das feridas cutâneas em camundongos diabéticos e reparação de defeitos ósseos críticos, respectivamente.

Atualmente, as pesquisas em Medicina Veterinária têm utilizado felinos, caninos, equinos, ovinos e caprinos. Em gatos, MARTIN et al. (2002) realizaram o isolamento e caracterização de CTMs 2007), tecido adiposo e medula óssea (Silveira et al., 2009) e do cordão umbilical (LEE et al., 2013).

Em equinos já foi comprovado o isolamento deste tipo celular em tecido adiposo (CARVALHO et al., 2009), cordão umbilical (REED \& JONHSON, 2012), e medula óssea (Seo et al., 2012), sendo realizadas diversas pesquisas voltadas para o uso de células-tronco na reparação de lesões como de tendões, articulações e ligamentos (PACINI et al., 2007; GODWIN et al., 2012; SOLE et al., 2012; FERRIS et al., 2013).

Isolamento de células-tronco também foram realizados em ratos (KADIYALA et al., 1997a; LENNON \& CAPLAN, 2006), camundongos (BITTENCOURT et al., 2006; YAMAMOTO et al., 2007; SUNG et al., 2008), ovinos, sendo utilizadas amostra de 
tecido adiposo e cordão umbilical (FADEL et al., 2011) e em tecido adiposo e fluido amniótico de caprinos (REN et al., 2012;

PRATHEESH et al., 2013).

\section{Considerações finais}

A capacidade de se diferenciar em diversos tipos celulares das células-tronco mesenquimais é de grande interesse da comunidade cientifica devido, principalmente, a sua importância para o sucesso das terapias celulares, reestabelecendo de maneira mais rápida o funcionamento normal de tecidos lesados.

Atualmente, com o avanço do conhecimento sobre células-tronco e das técnicas moleculares, a ciência conseguiu gerar informações importantes para o diagnóstico e tratamento de diversas doenças. Dessa forma, os avanços nas pesquisas sobre terapias celular têm colaborado para o bem-estar animal, proporcionando uma melhor qualidade de vida, redução da dor e do período de recuperação dos mesmos.
Considerando a vasta capacidade das CTMs, pesquisas mais abrangentes, destinadas a outros interesses médicoveterinários, poderiam ser realizadas com o intuito de ampliar a utilização e importância destas células. A implementação de linhagens de célulastronco como ferramenta para o isolamento de patógenos em cultivo celular se apresenta como potencial alternativa as pesquisas com células indiferenciadas, não se restringindo apenas ao seu uso em terapias regenerativas.

\section{Referências Bibliográficas}

AMERSHAM BIOSCIENCES. FicollPaque Plus. For in vitro isolation of lymphocytes. New Jersey, 18 p, 2002.

ARGÔLO-NETO, N. M. Tratamento de feridas cutâneas experimentais em camundongos (Mus musculus C57BL/6) diabéticos com células-tronco mesenquimais aplicadas de forma isolada e associadas ao plasma autólogo rico em plaquetas. Tese de Doutorado em 
Medicina Veterinária, Departamento de Veterinária, Universidade Federal de Viçosa, MG, 121p, 2009.

BARROS, S.V.G.; DEL CARLO, R. J.; VIROLIA, M. I.; GALVÃO, S. R.; MAIA FILHO, A.; OLIVEIRA, D. R. Autoenxerto percutâneo de medula óssea. II Reparação de falhas segmentares produzidas no rádio de coelhos. Ciência Rural. 31:627-632, 2001.

BIANCO, P.; ROBEY, P. G.; SIMMONS, P. J. Mesenchymal stem cells: revisiting history, concepts, and assays. Cell Stem Cell. 2:313-319, 2008.

BITTENCOURT, R.A.C.; PEREIRA, H.R.; FELISBINO, S.L.; MURADOR, P.; OLIVEIRA， A.P.E.; DEFFUNE， E. Isolamento de células tronco mesenquimais da medula óssea. Acta Ortopédica Brasileira, 14(1):22-24, 2006.

BJORNSON， C. R.; RIETZE， R. L.; REYNOLDS, B. A.; MAGLI, M. C.; VESCOVI, A. L. Turning Brain into Blood: A Hematopoietic Fate Adopted by
Adult Neural Stem Cells in Vivo. Science, 283(5401): 534-537, 1999.

BOBIS, S.; JAROCHA, D.; MAIKA, M. Mesenchymal stem cells: characteristics and clinical applications. Folia Histochemica et Cytobiological. 44:215230, 2006.

BLAU, H. M.; BRAZELTON T. R.; WEIMANN J. M. The evolving concept of a stem cell: entity or function? Cell. 105(7):829-41, 2001.

BYDLOWSKI, S. P.; DEBES, A. A.; MASELLI, L. M. F.; JANZ, F. L. Características biológicas das célulastronco mesenquimais. Revista Brasileira de Hematologia e Hemoterapia. São Paulo, 31(Supl. 1): 25-35, 2009.

CAPLAN, A.I. Why are MSCs therapeutic? New data: new insight. Journal of Pathology. 217:318-324, 2009. CARVAlHO, A. M.; ALVEZ, A. L. G.; GOLIM, M. A.; MOROZ, A.; HUSSINI, C. A.; OLIVEIRA, P. G. G.; DEFFUNE, E. Isolation and immunophenotypic 
characterization of mesenchymal stem cells derived from equine species adipose tissue. Veterinary Immunology and Immunopathology. 132:303-306, 2009.

CLARKE, D. L.; JOHANSSON, C. B.; WILBERTZ, J.; VERESS, B.; NILSSON, E.; KARLSTROM, H.; LANDAHL, U.; FRISÉN, J. Generalized Potential of Adult Neural Stem Cells. Science, 288(5471):1660-1663, 2000.

CSAKI, C.; MATIS, U.; MOBASHERI, A.; YE, H.; SHAKIBAEI, M. Chondrogenesis, osteogenesis and adipogenesis of canine mesenchymal stem cells: a biochemical, morphological and ultrastructural study. Histochemistry and Cell Biology. 128(6):507-520, 2007.

DVORAKOVA, J.; HRUBA, A.; VELEBNY, V.; KUBALA, L. Isolation and characterization of mesenchymal stem cell population entrapped in bone marrow collection sets. Cell Biology International. 32:1116-1125, 2008.
FADEL, L. Caracterização morfológica de células-tronco mesenquimais de sangue umbilical e de tecido adiposo coletados por via intra-abdominal e uterina em ovinos. Dissertação de mestrado, Universidade de São Paulo, 57 p, 2009.

FERRIS, D.J.; FRISBIE, D.D.; KISIDAY, J.D.; MCILWRAITH， C.W.; HAGUE, B.A.; MAJOR, M.D.; SCHNEIDER, R.K.; ZUBROD, C.J.; KAWCAK, C.E.; GOODRICH, L.R. Clinical followup of thirty-three horses treated for stifle injury with bone marrow derived mesenchymal stem cells intra-articularly. Veterinary Surgery, in press. 2013.

FODOR, W. L. Tissue engineering and cell based therapies, from the bench to the clinic: the potential to replace, repair and regenerate. Reprod Biol Endocrinol. 1:102, 2003.

FRESHNEY, R.I. Culture of Animal Cells, a Manual of Basic Technique. 5 ed. Editora John Wiley \& Sons. Nova Jersey. 672 p, 2005. 
FRIEDENSTEIN, A. J. P. I.; in children with osteogenesis imperfect.

PETRAKOVA, K. V. Osteogenesis in transplants of bone marrow cells. The Journal of Embryological Experimental Morphology. 16:381-390, 1966.

FRIEL E, SAR S, MEE JP. Embryonic stem cells: understanding their history, cell biology and singnalling. Adv Drug Deliv Rev. 57:1894-903, 2005.

GODWIN, E.E.; YOUNG, N.J.; DUDHIA, J.; BEAMISH, I.C.; SMITH, R.K. Implantation of bone marrow-derived mesenchymal stem cells demonstrates improved outcome in horses with overstrain injury of the superficial digital flexor tendon. Equine Veterinary Journal. 44:25-32, 2012.

HORWITZ, E. M.; PROCKOP, D. J.; FITZPATRICK, L. A.; KOO, W. W.; GORDON, P. L.; NEEL, M.; SUSSMAN, M.; ORCHARD, P.; MARX, J. C.; PYERITZ, R. E.; BRENNER, M. K. Transplantability and therapeutic effects of bone marrow-derived mesenchymal cells
Nat Med.5:309-313, 1999.

HUSS, R. Cells from various sources isolation of primary and immortalized CD34- hematopoietic and mesenchymal stem. Stem Cells. 18(1):1-9, 2000.

ISLAM, A. A new, fast and convenient method for layering blood or bone marrow over density gradient medium. Journal of Clinical Pathology. Londres, 48(7):686688, 1995.

JAVAZON, E.H.; BEGGS, K.J.; FLAKE, A.W. Mesenchymal stem cells: paradoxes of passaging. Experimental Hematology. Copenhagen, 32(5):414-425, 2004.

JONES, E. A.; KINSEY, S. E.; ENGLISH, A.; JONES, R. A.; STRASZYNSKI, L.; MEREDITH, D. M.; MARKHAM, A. F.; JACK, A.; EMERY, P.; MCGONAGLE, D. Isolation and characterization of bone marrow multipotential Mesenchymal progenitor cells. Arthritis Rheum. 46:33493360, 2002. 
KADIYALA, S.; JAISWAL, N.; L.; BOUZAS L. F.; ABDELHAY E.

BRUDER, S. P. Culture-expanded, bone marrowderived mesenchymal stem cells can regenerate a critical-sized segmental bone defect. Tissue engineering. 3(2):173185, 1997a.

KADIYALA， S.; YOUNG， R.G.; THIEDE, M.A.; BRUDER, S.P. Culture expanded canine mesenchymal stem cells possess osteochondrogenic potential in vivo and in vitro. Cell transplant. 6(2):125-134, $1997 b$.

KRAMPERA, M.; COSMI, L.; ANGELI, R.; PASINI, A.; LIOTTA, F.; ANDREINI, A.; SANTARLASCI, V.; MAZZINGHI, B.; PIZZOLO, G.; VINANTE, F.; ROMAGNANI, P.; MAGGI, E.; ROMAGNANI, S.; ANNUNZIATO, F. Role for Interferon-g in the Immunomodulatory Activity of Human Bone Marrow Mesenchymal Stem Cells. Stem Cells.24:386-398, 2006.

LAZZAROTTO-SILVA C.; BINATO R.; ROCHER B. D.; COSTA J.A.; PIZZATTI
Similar proteomic profiles of human mesenchymal stromal cells from different donors. Cytotherapy. 11(3):268-77, 2009. LEE, R. H.; KIM, B.; CHOI, I.; KIM, H.; CHOI, H. S.; SUH, K; BAE, Y. C.; JUNG, J. S. Characterization and expression analysis of mesenchymal stem cells from human bone marrow and adipose tissue. Cellular Physiology and Biochemistry. 14:311-324, 2004.

LEE, K. S.; NAH, J.-J.; LEE, B.-C.; LEE, H.T.; LEE, H.-S.; SO, B.-J.; CHA, S.-H. Maintenance and characterization of multipotent mesenchymal stem cells isolated from canine umbilical cord matrix by collagenase digestion. Research in Veterinary Science 94:144-151, 2013.

LENNON, D.P. \& CAPLAN, A.I. Isolation of rat marrow-derived mesenchymal stem cells. Experimental Hematology. 34:1606-1607, 2006.

MAMBELLI, L.I.; SANTOS, E. J.; FRAZÃO, P. J.; CHAPARRO, M. B.; 
KERKIS, A.; ZOPPA, A. L.; KERKIS, I. Characterization of equine adipose tissuederived progenitor cells before and after cryopreservation.

Tissue

Engineerin.15(1):87-94, 1999.

MARTIN, D.R.; COX, N.R.; HATHCOCK, T.L.; NIEMEYER, G.P.; BAKER, H.J. Isolation and characterization of multipotential mesenchymal stem cells from feline bone marrow. Experimental hematology. 30:879-886, 2002.

MEIRELLES, L.S.; CAPLAN, A. L.; NARDI, N. B. In search of the in vivo identity of mesenchymal stem cells. Stem Cells. 26:2287-2299, 2008.

MEIRELlES, L. S., CHAGASTELlES, P. C., NARDI, N. B. Mesenchymal stem cells reside in virtually all post-natal organs and tissues. Journal of Cell Science, 119:2204-2213, 2006.

MIAO, Z.; JIN, J.; CHEN, L.; ZHU, J.; HUANG, W.; ZHAO, J.; QIAN, H.; ZHANG, X. Isolation of mesenchymal stem cells from human placenta: Comparison with human bone marrow mesenchymal stem cells. Cell Biology International. 30:681-687, 2006.

MINGUELL, J.J.; CONGET, P.; ERICES, A. Biology and clinical utilization of mesenchymal progenitor cells. Brazilian. Journal of Medical and Biological Research. 33(8):881-887, 2000.

MONTEIRO, B.S. Tratamento de defeitos críticos em calvária de camundongos com células-tronco mesenquimais associadas ou não ao plasma rico em plaquetas. Tese (Doutorado Medicina Veterinária) Departamento de Veterinária, Universidade Federal de Viçosa, MG, 109p, 2009.

OLIVEIRA, B.J.N.A. Enxerto osteocondral alógeno, associado á inoculação de células mononucleares $d a$ medula óssea e proteína morfogenética óssea no reparo do sulco troclear de coelhos. Dissertação de Mestrado em Ciências Veterinárias, Faculdade de 
Medicina Veterinária, Universidade

Federal de Uberlândia, Uberlândia, 53p, 2009.

PACINI, S.; SPINABELLA, S.; TROMBI, L.; FAZZI, R.; GALIMBERTI, S.; DINI, F.; CARLUCCI, F.; PETRINI, M. Suspension of bone marrow-derived undifferentiated mesenchymal stromal cells for repair of superficial digital flexor tendon in race horses. Tissue Engineering. 13:2949-2955, 2007.

PEREIRA, L. P. A importância do uso das células-tronco para saúde pública. Ciência \& Saúde Coletiva. 13(1): 7-14, 2008.

PEREIRA, I.S.O.; PONTES, P.; EÇA, L.P.; FERREIRA, A.T.; MAZZETTI, P.M.V.; SILVA, L.; SOUZA, F.C. Protocolo piloto de separação e quantificação de células-tronco de tecido adiposo de coelhos para posterior uso em laringe. Acta ORL. São Paulo, 26(3):11-16, 2008.

PHINNEY, D. G.; KOPEN, G.; RIGHTER, W.; WEBSTER, S.;
TREMAIN, N.; PROCKOP, D. J. Donor variation in the growth properties and osteogenic potential of human marrow stromal cells. J Cell Biochem. 75:424-436, 1999.

PITTENGER, M.F.; MACKAY, A.M.; BECK, S.C.; JAISWAL， R.K.; DOUGLAS, R.; MOSCA, J.D.; MOORMAN, M.A.; SIMONETTI, D.W.; CRAIG, S.; MARSHAK, D.R. Multilineage potential of adult human mesenchymal stem cells. Science. 284(5411):143-147, 1999.

PRATHEESH, M.D.; GADE, N. E.; KATIYAR, A. N.;. DUBEY, P. K.; SHARMA, B.; SAIKUMAR, G.; AMARPAL; SHARMA, G.T. Isolation, culture and characterization of caprine mesenchymal stem cells derived from amniotic fluid. Research in Veterinary Science. 94:313-319, 2013.

PROCKOP, D. J. Marrow stromal cells as stem cells for nonhematopoietic tissues. 
Science. Pennsylvania, 276(5309):71-74, 1997.

PROCKOP， D.J.; GREGORY， C.A.; SPEES, J.L. One strategy for cell and gene therapy: harnessing the power of adult stem cells to repair tissues. Proceedings of the National Academy of Science of the United States of America. 100(1):1191711923, 2003.

REBELATTO, C. K.; AGUIAR, A. M.; MORETÃO, M. P,; SENEGAGLIA, A. C.; HANSEN, P.; BARCHIKI, F.; OLIVEIRA, J.; MARTINS, J. KULIGOVSKI, C.; MANSUR, F. CHRISTOFIS, A.; AMARAL, V. F.; BROFMAN, P. S.; GOLDENBERG, S.; NAKAO, L. S.; CORREA, A. Dissimilar differentiation of mesenchymal stem cells from bone marrow, umbilical cord blood, and adipose tissue. Experimental Biology and Medicine. 233:901-913,

REED S. A.; JOHNSON S. E. 2012. Refinement of Culture Conditions for Maintenance of Undifferentiated Equine
Umbilical Cord Blood Stem Cells. Journal of Equine Veterinary Science. 32:360-366, 2008.

REN, Y.; WU, H.; ZHOU, X.; WEN, J.; JIN, M.; CANG, M.; GUO, X.; WANG, Q.; LIU, D.; MA, Y. Isolation, expansion, and differentiation of goat adipose-derived stem cells. Research in Veterinary Science. 93:404-411, 2012.

SEO, J.-P.; TSUZUKI, N.; HANEDA, S.; YAMADA, $\quad$ K.; $\quad$ FURUOKA, $\quad$ H.; TABATA, Y.; SASAKI, N. Proliferation of equine bone marrow-derived mesenchymal stem cells in gelatin/btricalcium phosphate sponges. Research in Veterinary Science. 93:1481-1486, 2012. SILVEIRA, A. C. C.; LIMA, R. S.; PENHA, E. M.; MACAMBIRA, S. G.; SOARES, M. B. P.; RIBEIRO-DOSSANTOS, R.; BARROUIN-MELO, S. M.; AGUIAR, P. H. P. Harvest and characterization of mesenchymal canine stem cells from adipose tissue and bone marrow. In: 8th International Veterinary 
Martins et al., Revista Brasileira de Higiene e Sanidade Animal (v.8, n.2) p. 181 - 202, abr - jun (2014

Immunology Symposium, Ouro Preto. Experimental Biology and Medicine. Veterinary Immunology and 234:1-9, 2009.

Immunopathology. 128:342, 2009.

TROPEL, P.; NÖEL D.; LEGRAND P.;

SOLE, A.; SPRIET, M.; GALUPPO, L.D.; BENABID, A.; BERGER, F. Isolation and

PADGETT, K.A.; BORJESSON, D.L.; characterization of mesenchymal stem cell WISNER, E.R.; BROSNAN, R.J.; VIDAL, M.A. Scintigraphic evaluation of intraarterial and intravenous regional limb perfusion of allogeneic bone marrowderived mesenchymal stem cells in the normal equine distal limb using (99 m) TcHMPAO. Equine Veterinary Journal. 44, 594-599, 2012.

SUNG, J.H.; YANG, H.-M.; PARK, J.B.; CHOI, G.-S.; JOH, J.-W, KWON, C.H.; CHUN, J.M., LEE, S.-K.; KIM, S.-J. Isolation and characterization of mouse mesenchymal stem cells. Transplantation proceedings. 40:2649-2654, 2008.

TAPP, H.; HANLEY, E. N.; PATT, J. C.; GRUBER, H. E. Adipose-derived stem cells: characterization and current application in orthopaedic tissue repair. from adult mouse bone marrow. Experimental cell research. 295:395-406, 2004.

UCHIDA, N.; BUCK, D. W.; HE, D.; REITSMA, M. J.; MASEK, M.; PHAN, T. V.; TSUKAMOTO, A. S.; GAGE, F. H.; WEISSMAN, I. L. Direct isolation of human central nervous system stem cells. Proceedings of the National Academy of Sciences. 97(26): 14720-14725, 2000.

WAGNER, W.; WEIN, F.; SECKINGER, A.; FRANKHAUSER, M.; WIRKNER, U.; KRAUSE, U.; BLAKE, J.; SCHWAGER, C.; ECKSTEIN, V.; ANSORGE, W.; HO, A.D. Comparative characteristics of mesenchymal stem cells from human bone marrow, adipose tissue, and umbilical cord blood. Experimental Hematology. 33:1402-1416, 2005. 
WAN, C.D.; CHENG, R.; WANG, H. B.; LIU, T. Immunomodulatory effects of mesenchymal stem cells derived from adipose tissues in a rat orthotopic liver transplantation model. Hepatobiliary \& Pancreatic Diseases International. 7:2933, 2008.

WEXLER， S.A.; DONALDSON， C.; DENNING-KENDALL， P.; RICE， C.; BRADLEY, B.; HOWS, J.M. Adult bone marrow is a rich source of human mesenchymal stem cells but umbilical cord and mobilized adult blood are not. British Journal of Haematology. London, 121(2):368-374, 2003.

WILSON A. \& TRUMPP A. Bone-marrow haematopoietic-stem-cell niches. Nat Rev Immunol. 6:93-106, 2006.

WOODBURY, D.; SCHWARZ, E.J.; PROCKOP, D.J.; BLACK, I.B. 2000. Adult rat and human bone marrow stromal cells differentiate into neurons. Journal of Neuroscience Research. 61(4):364-370, 2006.
YAMAMOTO, N.; AKAMATSU, H.; HASEGAWA, $\quad$ S.; $\quad$ YAMADA, T.; NAKATA, S.; OHKUMA, M.; MIYACHI, E.-I.; MARUNOUCHI, $\quad$ T.; MATSUNAGA, K. Isolation of multipotent stem cells from mouse adipose tissue. Journal of Dermatological Science. 48(1):43-52, 2007.

ZAGO, M. A., COVAS, D. T. Pesquisas com células-tronco: aspectos científicos, éticos e sociais. Seminário Instituto Fernando Henrique Cardoso, 1:1-20, 2004.

ZAGO, M. A. Terapia com células-tronco: fundamentos, oportunidades e obstáculos. Revista da sociedade brasileira de hipertensão. 8(4):145-150, 2005.

ZUCCONI, E.; VIEIRA, N. M.; BUENO, D. F.; SECCO, M.; JAZZEDJE, T.; AMBROSIO, C. E.; PASSOS-BUENO, M. R.; MIGLINO, M. A.; ZATZ, M. Mesenchymal stem cells derived from canine umbilical cord vein - a novel source 
Martins et al., Revista Brasileira de Higiene e Sanidade Animal (v.8, n.2) p. 181 - 202, abr - jun (2014

for cell therapy studies. Stem Cells and

Development, in proof, 1-33, 2009.

ZUK, P. A.; ZHU, M.; MIZUNO, H.;

HUANG J.; FUTRELL, J. W.; KATZ, A.

J.; BENHAIM, P.; LORENZ, H. P.;

HEDRICK, M. H. Multilineage cells from

human adipose tissue: implications for

cell-based therapies. Tissue Engineering.

$7(2): 211-228,2001$. 